\title{
Influence of Artifical Discontinuities in Rocks on the Propagation of Ultrasonic $\boldsymbol{P}$-Waves
}

\author{
Z. KAMACI ${ }^{a, *}$ AND B. AKGÜNEŞ ${ }^{b}$ \\ ${ }^{a}$ Süleyman Demirel University, Faculty of Engineering, Department of Geophysical Engineering, Isparta, Turkey \\ ${ }^{b}$ Süleyman Demirel University, Graduate School of Natural and Applied Sciences, \\ Department of Geophysical Engineering, Isparta, Turkey \\ (Received March 13, 2017; in final form August 9, 2017) \\ In this work, experiments were conducted on rectangular prismatic samples with dimensions of $60 \times 60 \times$ \\ $360 \mathrm{~mm}^{3}$, which were cut from the rock blocks with no joint or anisotropy. Rock samples were obtained from \\ different quarries in Turkey, known by the rock type as Afyon Çay marble, Burdur red limestone, Afyon gray, \\ Lymra limestone, Muğla dolomite, Denizli travertine, and Isparta andesite. Experimental results indicated an \\ increase in seismic wave attenuation as the number of artificial joints increased. However, seismic wave attenuation \\ rate was found to be higher on the samples with parallel joint pattern than the samples which consisted of various \\ directional joint pattern. This feature has explained the importance of seismic velocity anisotropy in rocks. The \\ relationship between the number of joints in seven different rock samples and ultrasonic $P$-wave velocity was \\ examined statistically and the results were evaluated together with similar studies in the literature.
}

DOI: 10.12693/APhysPolA.133.1144

PACS/topics: ultrasonic pulse velocity, joint number, the wave attenuation

\section{Introduction}

Seismic methods are often used to identify and characterize the dynamic properties of the rocks via wave propagation in both field and the laboratory. Since this technique is non-detrimental and can easily be applied it is frequently employed in earthquake, geotechnical, and geophysical engineering.

In these studies [1,2], it is stated that there is a close relationship between rock properties and seismic velocity. There are many factors affecting the seismic velocity of rocks such as rock type, density, particle size, shape, porosity, anisotropy, water content, pressure, and temperature. In addition, rock alteration, presence of bedding planes and joint properties also are important factors on seismic velocity.

Several experimental studies [3-9] indicate the importance of crack presence in rocks. Hence, numerical studies were conducted to emphasize the importance of the seismic velocity anisotropy for an isotropic matrix containing circular cracks in the rocks [10]. The elastic modulus of cracked rocks were calculated by the geometry of the crack tensor which reveal the cracks in the rock clusters [11].

Experimental studies have shown how the seismic velocity changed depending on the anisotropy and stresses in the cracks of rocks [12-16]. By examining the relationships between the number of artificial joints and seismic velocities for different rock types, the decrease in seismic velocities with increasing number of joints was monitored $[17,18]$. The evaluation of joints (frequency, trace

*corresponding author; e-mail: zuheyrkamaci@sdu.edu.tr length and orientation of joint sets) bears great importance in rock mechanics since shape of the block, their volume in the rock masses and their mechanical strength (compression and shear strength, deformation modulus, etc.) are all affected by joint density in rock masses [18]. In these researches, the samples contained only parallel artificial joints rather than the variable directional joints.

However, the work [19] is the only example in which both parallel and variable oriented joints on a single marble have been considered to examine the changes in $P$ wave propagation.

Researchers [20] have shown that $P$-waves as a nondetrimental technique can provide accurate information about the presence of discontinuities such as joints and cracks in rock, its homogeneity, alteration degree, and porosity. Similarly, in works [21-25] researchers have frequently utilized the ultrasonic pulse velocity (UPV) to determine the rock quality, to evaluate their physicomechanical properties when the rock has microscopic fissures and karstic pores such as in limestones. Since ultrasonic techniques are non-destructive and easy to apply, both for site and laboratory conditions, they are increasingly being used in geotechnical applications [26]. There are number of factors that influence the sound velocity of rocks. Main factors influence the $P$-wave velocity: density, rock type, shape and grain size, porosity, anisotropy, porewater, confining pressure, temperature, rock mass properties. In addition to these factors, weathering, alteration zone, bedding planes, and joint properties (filling materials, roughness, water, dip and strike, etc.) also influence the sound velocity. In such works, sedimentary, igneous, and metamorphic rocks samples are used. But, metamorphic rocks are not preferred because of their anisotropic characteristic [26]. 
In this study, the aim has been to determine the influence of artificially created joints in parallel and variable directions, on seven different rock types of different sedimentary, metamorphic and igneous (volcanic) origins, as of dolomite, limestone, Burdur Red, travertine, Afyon Çay, Afyon Gray, and andesite by UPV. This study is performed based on the techniques and methods used in the study given in [19].

\section{Laboratory studies}

Two prismatic rock samples with dimensions of $60 \times$ $60 \times 360 \mathrm{~mm}^{3}$ were prepared from each of seven different rock types quarried from different locations in Turkey (Table I - at the end). Each of rock samples were cut to form artificial rock joints in both parallel and variable directions (Fig. 1). Joint walls were machined to ensure the smoothness and full contact between the joint walls.

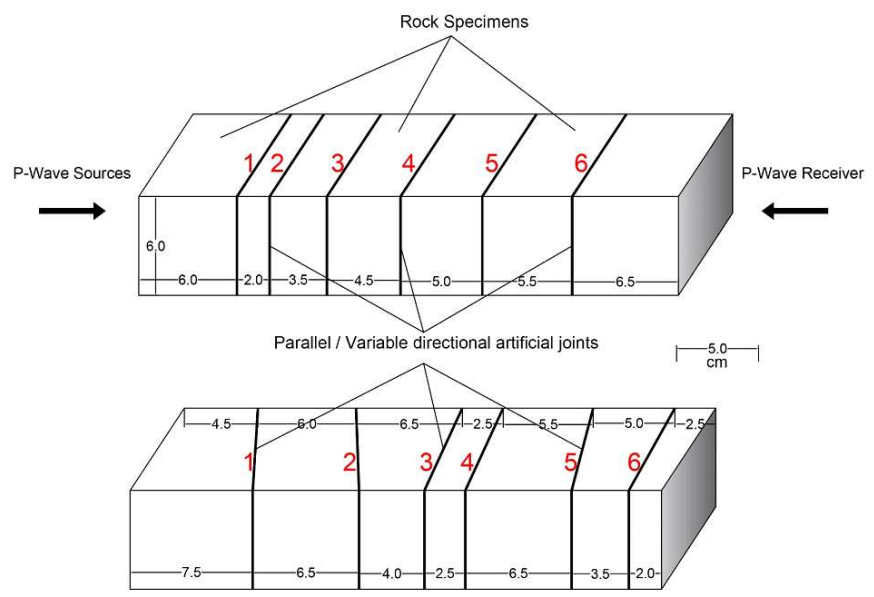

Fig. 1. (a) Schematic view of a rock sample with 6 parallel artificial joints. (b) Schematic view of a rock sample with 6 oriented artificial joints.

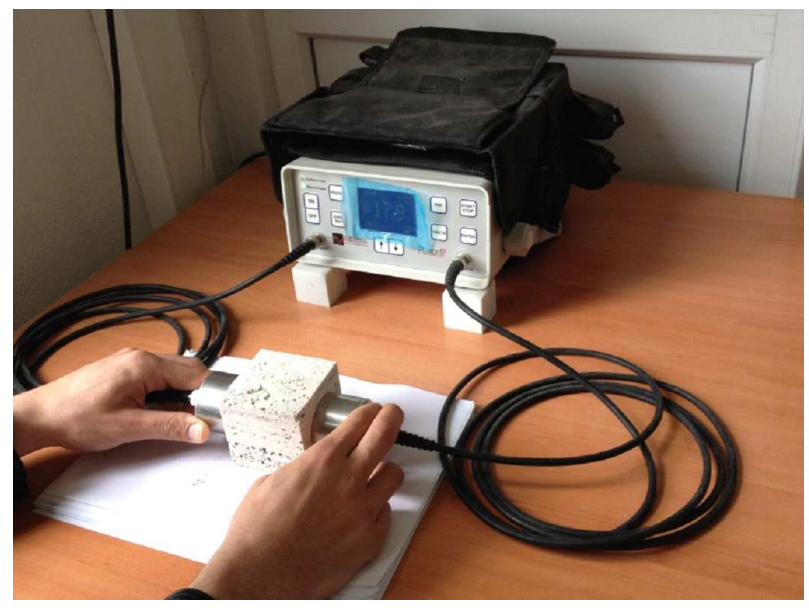

Fig. 2. Ultrasonic Pundit pulse generator device used for $P$-wave measurements.
Initial UPV values were measured on each prismatic rock sample using Pundit pulse generator with $54 \mathrm{kHz}$ frequency (Fig. 2). The test results of the measurements are given in Tables I (at the end) and II separately for all rocks. Variations in UPV attenuations (\%) with number of joints for both parallel and variable direction joints are plotted and displayed in Figs. 3-6. Inverse linear relations between the number of joints and the $P$-wave velocities were obtained for the parameter ranges of the

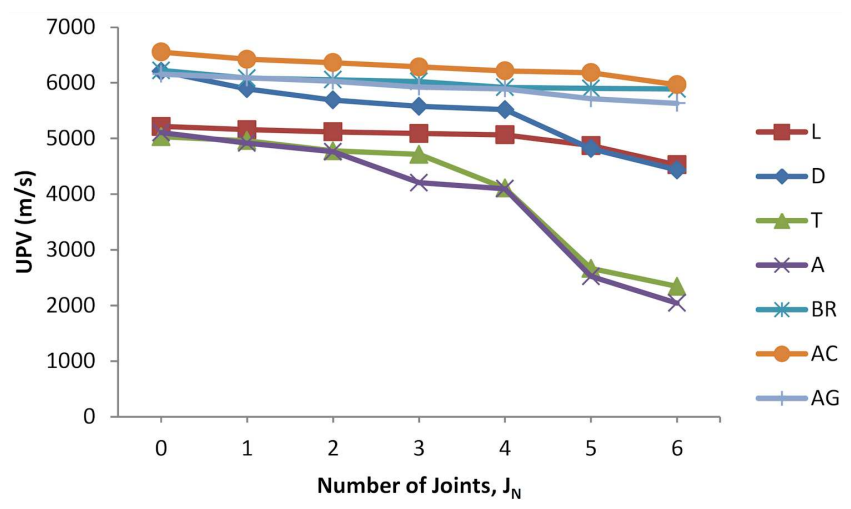

Fig. 3. Graphical view of UPV and parallel joint numbers $\left(J_{N}\right)$ for all parallel jointed rock types.

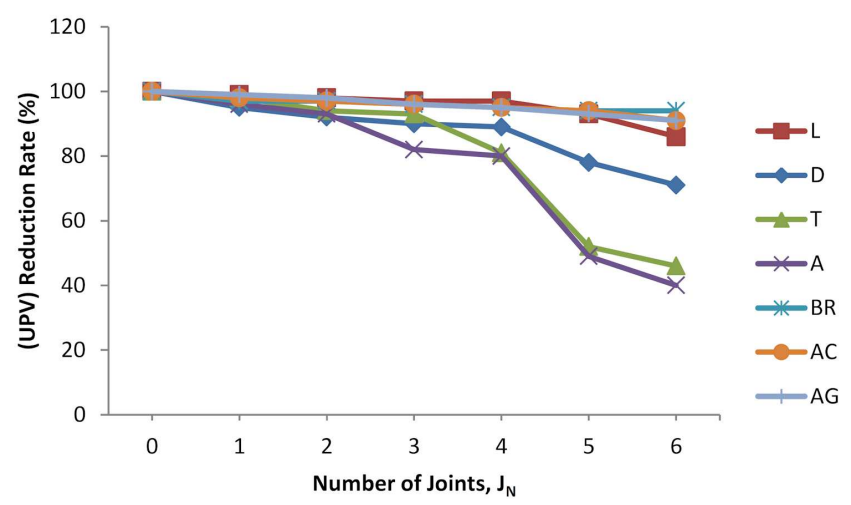

Fig. 4. UPV reduction rates (\%) and parallel joint numbers $\left(J_{N}\right)$ for all parallel jointed rock types.

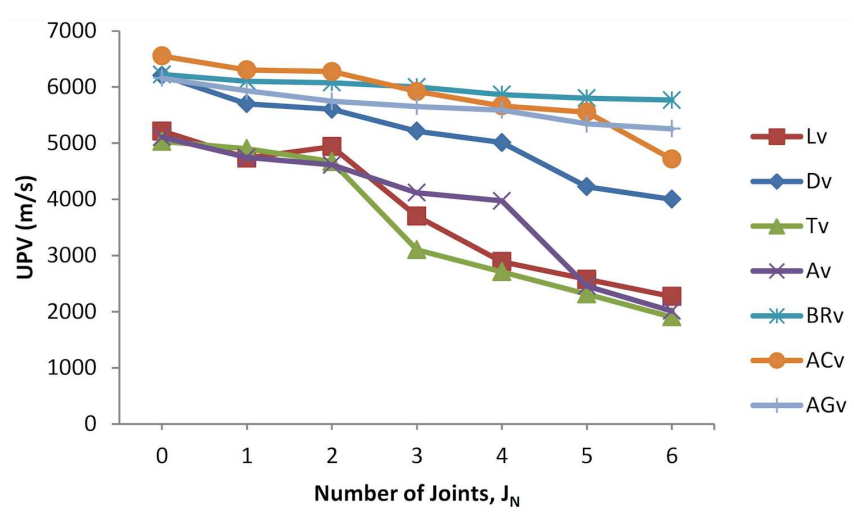

Fig. 5. Graphical view of UPV and oriented joint numbers $\left(J_{N}\right)$ for all oriented jointed rock types. 


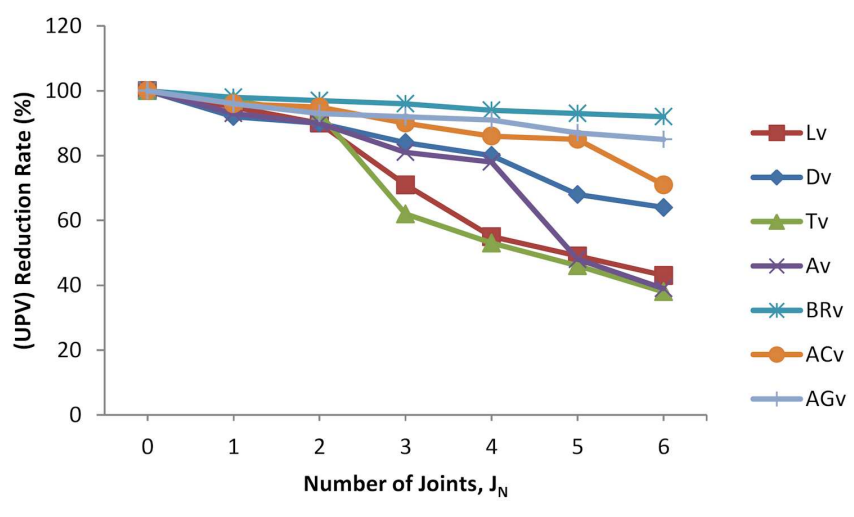

Fig. 6. UPV reduction rates $(\%)$ and oriented joint numbers $\left(J_{N}\right)$ for all oriented jointed rock types.

experimental work. The $P$-wave velocity decreases with an increase in the number of joints. The slopes of the regression lines were explained as the sound velocity index (SVI). High strength rocks exhibit higher SVI than the low strength rocks. Further research is necessary to investigate how the derived equations and the SVI vary with a larger number of joints, varying rock type and varying water content [23]. The physical properties of the specimens such as dry unit weight, saturated unit weight, water absorption and effective porosity were determined in accordance with [27]. This is standard where the analyses were done at room temperature under dry conditions. The effective porosity of rock specimens was determined using saturation and buoyancy techniques. The rock samples were immersed in water and saturated for $48 \mathrm{~h}$ with a constant speed agitation in order to remove the air trapped inside. Then, the samples were transferred underwater to a basket in an immersion bath and their saturated-submerged weights were measured with a scale having $0.01 \mathrm{~g}$ accuracy. Later, the surface of the specimens was dried with a moist cloth and their saturated-surface-dry weights were measured outside water. Bulk sample volumes were found from weight differences between saturated-surface-dry weight and saturated-submerged weight. The dry mass of specimens was determined after oven drying at a temperature of $105^{\circ} \mathrm{C}$ for a period of at least $24 \mathrm{~h}$. The effective pore volumes were determined from weight difference between saturated-surface-dry weight and dry sample weight.

\section{Results and discussion}

For all the rock samples tested, the variations in UPV with respect to the number of parallel and variably oriented artificial joints $\left(J_{N}\right)$ were statistically analysed by the least square regression method and the results were displayed in Figs. 7 and 8 for the best fits and related coefficients $\left(R^{2}\right)$.

In this study, the results obtained from 7-different rock samples were plotted on the same graph in order to simplify the evaluations of the results (Figs. 3-6).

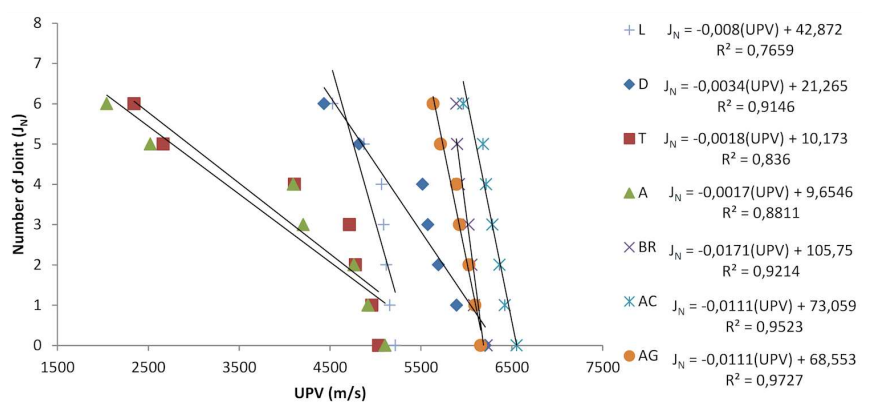

Fig. 7. Graphical view for SVI values in relation with UPV and parallel joint numbers $\left(J_{N}\right)$ for all parallel jointed rock types

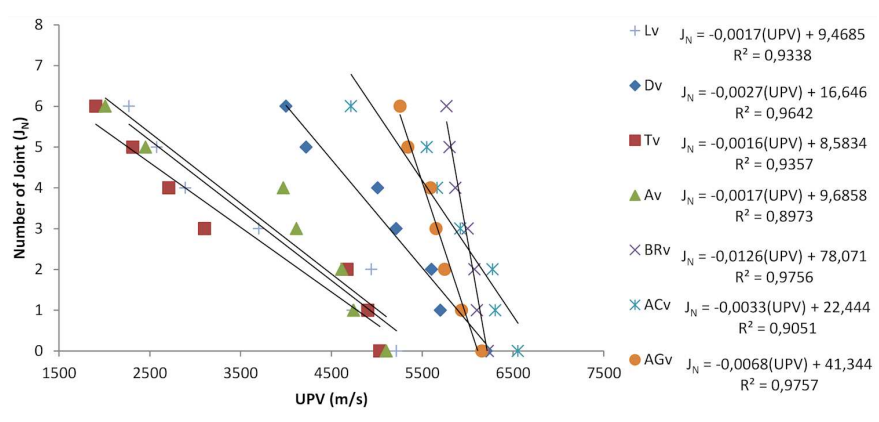

Fig. 8. Graphical view for SVI values in relation with UPV and oriented joint numbers $\left(J_{N}\right)$ for all oriented jointed rock types.

An inverse relationship was observed between the UPV and $J_{N}$ values for all the rock samples with parallel and variably oriented artificial joints as shown in Figs. 3-6. The reduction in UPV values was found to be around $30 \%$ higher, especially in andesite, Lymra, and travertine samples with oriented artificial joints when compared to those obtained from parallel artificial joints.

When Figs. 4 and 6 were assessed together, in travertine and andesite samples with parallel 5th and 6th artificial joints, reduction rate in UPV (\%) (or in seismic velocity attenuation) was found to be $60 \%$ while it was about $40 \%$ in the third variably oriented artificial joints, $50 \%$ in the 4 th oriented joint, $55 \%$ in the 5 th oriented joint, and $60 \%$ in the 6 th oriented joint. Accordingly, seismic velocity attenuations of approximately $30 \%$ were determined in andesite and travertine for both parallel and oriented artificial joints. In addition, in Lymra, a seismic velocity attenuations of approximately $10 \%$ was detected depending on the number of parallel joints (Fig. 6) owing to that the porosity of Lymra is very close to that of andesite and travertine (Table II). This indicates that seismic waves in Lymra is influenced from anisotropy when compared to the seismic waves in travertine and andesite. It is clear that seismic velocity attenuation is much higher than the other four rocks because of the high porosity of the andesite, lymra, and travertine. The results obtained from 
TABLE II

The names, locations, certain characteristics and laboratory analysis results of collected rocks.

\begin{tabular}{|c|c|c|c|c|c|c|c|c|c|}
\hline $\begin{array}{c}\text { Rock } \\
\text { sample }\end{array}$ & Location & $\begin{array}{l}\text { Rock } \\
\text { type }\end{array}$ & $\begin{array}{l}\text { Rock } \\
\text { class }\end{array}$ & Crystallization & Bedding & $\begin{array}{l}\mathrm{UPV} \\
{[\mathrm{m} / \mathrm{s}]}\end{array}$ & $\begin{array}{c}\text { Dry unit } \\
\text { weight } \\
\text { DUW } \\
{\left[\mathrm{g} / \mathrm{cm}^{3}\right]}\end{array}$ & $\begin{array}{c}\text { Effective } \\
\text { porosity } \\
n[\%]\end{array}$ & \begin{tabular}{|c} 
Sound \\
velocity \\
index \\
SVI $[\mathrm{s} / \mathrm{m}]$
\end{tabular} \\
\hline L (Lymra) & Finike-Antalya & limestone & sedimentary & fine & present & 5217 & 2.41 & 12.00 & 0.0080 \\
\hline $\mathrm{D}$ (dolomite) & Muğla & marble & metamorphic & coarse & present & 6206 & 2.70 & 0.51 & 0.0034 \\
\hline $\mathrm{T}$ (travertine) & Denizli & travertine & sedimentary & not visible to the eye & present & 5033 & 2.32 & 13.07 & 0.0018 \\
\hline A (andesite) & Isparta & andesite & igneous & medium-fine & absent & 5105 & 2.28 & 14.63 & 0.0017 \\
\hline BR (Burdur red) & Burdur & limestone & sedimentary & fine & absent & 6223 & 2.69 & 1.00 & 0.0171 \\
\hline AC (Afyon Çay) & Afyon-Çay & marble & metamorphic & medium-fine & present & 6554 & 2.67 & 1.44 & 0.0111 \\
\hline AG (Afyon grey) & Afyon & marble & metamorphic & medium-fine & present & 6157 & 2.70 & 0.47 & 0.0111 \\
\hline
\end{tabular}

Kahraman [17] and Altindağ and Güney [18] have unveiled that the UPV $(\mathrm{m} / \mathrm{s})$ decreases as the number of joints increases, however, the authors have not analyzed the influence of joint orientation.

When the relationships graphics between UPV and $J_{N}$ and the statement SVI as given in [17] were considered for all the samples and joint configurations tested in this work, the types of marbles may be listed in range of high to low inclination as follows: Afyon çay, Burdur Red, Afyon gray, Lymra, dolomite, travertine and andesite. Namely, the samples of Afyon Çay, Burdur red, and Afyon gray appear to have higher inclination and consequently have higher SVI values than other rock samples (Figs. 7 and 8). It can be concluded that as the inclination increases the rock will be characterized as sounder. Kurtuluş et al. [19] conclude that the UPV values decrease as the density of parallel and oriented joints increases. However, their work does not contain the physical properties of 7-different rock types and does not interpret the results together as conducted in this work.

\section{Conclusions}

It is known that discontinuity planes have an important influence on the sound velocity. The researchers have reported the following results based on the works on prismatic blocks with parallel joints using $p$-wave velocity tests:

- In this work, the relations between $J_{N}$ and UPV values of the rocks are shown on a single chart and the SVI values are determined from the inclinations. It can be seen that the SVI values become higher as the inclination of relation lines become higher. Hence, the rocks with high SVI values will have high seismic velocities and are classified as solid rocks.

- The results obtained in this study indicate that the UPV values of rocks will be attenuated as the number of joints increases. Especially, attenuation rate will be even higher and apparent for porous rock with oriented joints.

- As it is well known, the degree of jointing, which is one of the most important parameters influencing seismic velocities in rock mass must be considered by re- searchers and engineers when designing structures rock masses. The results of the present experiments confirm that the $P$-wave velocity decreases with an increase in the density of joints in rocks, agreeing with the results obtained by [23]. Furthermore, there is a good linear correlation between the number of joints and the reduction rates in $V_{p}(\%)$ indicating that the $P$-waves are attenuated rapidly as the number of joints increases.

In general, the rock samples have a very homogeneous structure when their ultrasonic velocities and SVI slope values are examined, showing that the discontinuities such as micro cracks and pores are very small. However, when the SVI inclination values of the travertine, andesite and Lymra rock samples are examined, it shows that micro cracks and pores are more intense. It is observed that SVI values are even lower in variable direction tests. This clearly shows how much the seismic $P$-waves in variable directions of rocks are affected by attenuation, and thus by anisotropy. Moreover, mineralogical composition and crystal structure of these rocks may also affect the seismic velocity. However, this effect may be different in each rock.

\section{Acknowledgments}

We like to thank to the Administration of Süleyman Demirel University for supporting this work by the Scientific Research Project (3560-YL1-13). In addition, we are grateful to Prof. Dr. Raşit Altinda ğ and Research Assistant Deniz Akbay for valuable supports during the laboratory works.

\section{References}

[1] D.U. Deere, R.P. Miller, Air Force Weapons Lab. Tech. Report No. AFWL-TR-65-116, Kirtland Base, New Mexico 1966.

[2] P. Gaviglio, Rock Mech. Rock Eng. 22, 299 (1989).

[3] K. Iida, T. Sugino, H. Furuhashi, M. Kumazawa, J. Earth Sci. Nagoya Univ. 15, 112 (1976).

[4] N.I. Gupta, J. Geophys. Res. 78, 6936 (1973).

[5] C. Wang, W. Lin, H.R. Wenk, J. Geophys. Res. 80, 1065 (1975).

[6] D. Lockner, J.B. Walsh, J.D. Byerlee, J. Geophys. Res. 82, 5374 (1977). 
[7] A. Idziak, Acta Geophys. Pol. 36, 101 (1988).

[8] A. Idziak, Seismic wave velocity anisotropy and its relation to crack orientation of rock masses Silesian Univ. Publ., Katowice 1992 (in Polish with English abstract).

[9] A. Idziak, I. Stan-Kleczek, in: Multiphysics Coupling and Long Term Behavior in Rock Mechanics, Eds. A. van Cotthem, R. Charlier, J.-F. Thimus, J.P. Tshibangu, Taylor \& Francis, London 2006, p. 551.

[10] D.L. Anderson, B. Minster, D. Cole, J. Geophys. Res. 79, 4011 (1974).

[11] M. Oda, Rock Mech. Rock Eng. 26, 89 (1974).

[12] A. Nur, G. Simmons, J. Geophys. Res. 74, 6667 (1969).

[13] M. King, N. Chaudhry, A. Shakeel, Int. J. Rock Mech. Mining Sci. 32, 155 (1995).

[14] C. Sayers, M. Kachanov, J. Geophys. Res. 100, 4149 (1995).

[15] C. Sayers, Geophys. Prospect 50, 85 (2000).

[16] Y. Gueguen, A. Schubnel, Tectonophysics 370, 163 (2003).

[17] S. Kahraman, J. Rock Mech. Min. Sci. 38, 729 (2001).
[18] R. Altındağ, A. Güney, in: Proc. 19th Int. Mining Congress and Fair of Turkey IMCET, Ed. A.H. Onur, Izmir (Turkey), 2005, p. 101.

[19] C. Kurtuluş, M. Üçkardeş, U. Sarı, Ş.O. Güner, Bull. Eng. Geol. Environ. 71, 231 (2012).

[20] İ. Uğur, N. Şengün, S. Demirağ, R. Altındağ, Ultrasonics 54, 1332 (2014).

[21] E. Vasanelli, D. Colangiuli, A. Calia, M. Sileo, M.A. Aiello, Ultrasonics 60, 33 (2015).

[22] L. Valdelon, M.H. De Freitas, M.S. King, Q.J. Eng. Geol. Hydrogeol. 29, 229 (1996).

[23] S. Kahraman, Ultrasonics 46, 341 (2007).

[24] O. Kılıç, Int. J. Rock Mech. Min. Sci. 43, 980 (2006).

[25] R. Fort, M.A. De Buergo, E.M. Perez-Monserrat, Int. J. Rock Mech. Min. Sci. 61, 296 (2013).

[26] M. Fener, J. Nondestruct. Eval. 30, 99 (2011).

[27] ISRM. The Complete ISRM Suggested Methods for Rock Characterization, Testing and Monitoring: 1974-2006, Eds. R. Ulusay, J.A. Hudson, Kozan Ofset Matbaacılık, Ankara 2007. 
TABLE I

Rock samples with their $J_{N}$, UPV, and rate of reduction in UPV with an increase in $J_{N}$ for parallel joints and variable directional joints.

\begin{tabular}{|c|c|c|c|c|c|c|c|}
\hline Rock sample & $\begin{array}{c}\text { Number } \\
\text { of joints } \\
\left(J_{N}\right)\end{array}$ & $\begin{array}{c}\mathrm{UPV}[\mathrm{m} / \mathrm{s}] \\
(P \text {-wave velocity })\end{array}$ & \begin{tabular}{|c|} 
Rate \\
of reduction \\
in UPV with \\
an increase \\
in $J_{N}[\%]$
\end{tabular} & Rock sample & $\begin{array}{c}\text { Number } \\
\text { of joints } \\
\left(J_{N}\right)\end{array}$ & $\begin{array}{c}\mathrm{UPV}[\mathrm{m} / \mathrm{s}] \\
(P \text {-wave velocity })\end{array}$ & $\begin{array}{c}\text { Rate } \\
\text { of reduction } \\
\text { in UPV with } \\
\text { an increase } \\
\text { in } J_{N}[\%]\end{array}$ \\
\hline \multirow{7}{*}{$\begin{array}{c}\text { L (Lymra } \\
\text { parallel } \\
\text { direction) }\end{array}$} & 0 & 5217 & 100 & \multirow{7}{*}{$\begin{array}{l}\text { Lv (Lymra } \\
\text { variable } \\
\text { direction) }\end{array}$} & 0 & 5217 & 100 \\
\hline & 1 & 5158 & 99 & & 1 & 4735 & 95 \\
\hline & 2 & 5118 & 98 & & 2 & 4939 & 90 \\
\hline & 3 & 5089 & 97 & & 3 & 3701 & 71 \\
\hline & 4 & 5067 & 97 & & 4 & 2891 & 55 \\
\hline & 5 & 4872 & 93 & & 5 & 2576 & 49 \\
\hline & 6 & 4527 & 86 & & 6 & 2271 & 43 \\
\hline \multirow{7}{*}{$\begin{array}{l}\mathrm{D} \text { (dolomite } \\
\text { parallel } \\
\text { direction) }\end{array}$} & 0 & 6206 & 100 & \multirow{7}{*}{$\begin{array}{c}\text { Dv } \text { (dolomite } \\
\text { variable } \\
\text { direction })\end{array}$} & 0 & 6206 & 100 \\
\hline & 1 & 5893 & 95 & & 1 & 5701 & 92 \\
\hline & 2 & 5692 & 92 & & 2 & 5603 & 90 \\
\hline & 3 & 5576 & 90 & & 3 & 5214 & 84 \\
\hline & 4 & 5519 & 89 & & 4 & 5011 & 80 \\
\hline & 5 & 4818 & 78 & & 5 & 4223 & 68 \\
\hline & 6 & 4434 & 71 & & 6 & 4001 & 64 \\
\hline \multirow{7}{*}{$\begin{array}{c}\mathrm{T} \text { (travertine } \\
\text { parallel } \\
\text { direction) }\end{array}$} & 0 & 5033 & 100 & \multirow{7}{*}{$\begin{array}{c}\text { Tv (travertine } \\
\text { variable } \\
\text { direction) }\end{array}$} & 0 & 5033 & 100 \\
\hline & 1 & 4960 & 98 & & 1 & 4902 & 97 \\
\hline & 2 & 4778 & 94 & & 2 & 4672 & 93 \\
\hline & 3 & 4713 & 93 & & 3 & 3103 & 62 \\
\hline & 4 & 4108 & 81 & & 4 & 2711 & 53 \\
\hline & 5 & 2664 & 52 & & 5 & 2314 & 46 \\
\hline & 6 & 2343 & 46 & & 6 & 1906 & 38 \\
\hline \multirow{7}{*}{$\begin{array}{c}\text { A (andesite } \\
\text { parallel } \\
\text { direction) }\end{array}$} & 0 & 5105 & 100 & \multirow{7}{*}{$\begin{array}{c}\text { Av (andesite } \\
\text { variable } \\
\text { direction) }\end{array}$} & 0 & 5105 & 100 \\
\hline & 1 & 4918 & 96 & & 1 & 4746 & 93 \\
\hline & 2 & 4762 & 93 & & 2 & 4614 & 90 \\
\hline & 3 & 4205 & 82 & & 3 & 4117 & 81 \\
\hline & 4 & 4096 & 80 & & 4 & 3972 & 78 \\
\hline & 5 & 2522 & 49 & & 5 & 2455 & 48 \\
\hline & 6 & 2043 & 40 & & 6 & 2011 & 39 \\
\hline \multirow{7}{*}{$\begin{array}{c}\text { BR (Burdur red } \\
\text { parallel } \\
\text { direction) }\end{array}$} & 0 & 6223 & 100 & \multirow{7}{*}{$\begin{array}{c}\text { BRv (Burdur red } \\
\text { variable } \\
\text { direction) }\end{array}$} & 0 & 6223 & 100 \\
\hline & 1 & 6085 & 97 & & 1 & 6103 & 98 \\
\hline & 2 & 6055 & 97 & & 2 & 6077 & 97 \\
\hline & 3 & 6024 & 96 & & 3 & 6001 & 96 \\
\hline & 4 & 5919 & 95 & & 4 & 5866 & 94 \\
\hline & 5 & 5899 & 94 & & 5 & 5802 & 93 \\
\hline & 6 & 5889 & 94 & & 6 & 5769 & 92 \\
\hline \multirow{7}{*}{$\begin{array}{c}\text { AC (Afyon Çay } \\
\text { parallel } \\
\text { direction) }\end{array}$} & 0 & 6554 & 100 & \multirow{7}{*}{$\begin{array}{c}\text { ACv (Afyon Çay } \\
\text { variable } \\
\text { direction) }\end{array}$} & 0 & 6554 & 100 \\
\hline & 1 & 6423 & 98 & & 1 & 6305 & 96 \\
\hline & 2 & 6364 & 97 & & 2 & 6276 & 95 \\
\hline & 3 & 6286 & 96 & & 3 & 5921 & 90 \\
\hline & 4 & 6216 & 95 & & 4 & 5664 & 86 \\
\hline & 5 & 6183 & 94 & & 5 & 5552 & 85 \\
\hline & 6 & 5966 & 91 & & 6 & 4716 & 71 \\
\hline \multirow{7}{*}{$\begin{array}{c}\text { AG (Afyon grey } \\
\text { parallel } \\
\text { direction) }\end{array}$} & 0 & 6157 & 100 & \multirow{7}{*}{$\begin{array}{c}\text { AGv (Afyon grey } \\
\text { variable } \\
\text { direction) }\end{array}$} & 0 & 6157 & 100 \\
\hline & 1 & 6093 & 99 & & 1 & 5933 & 96 \\
\hline & 2 & 6029 & 98 & & 2 & 5747 & 93 \\
\hline & 3 & 5924 & 96 & & 3 & 5653 & 92 \\
\hline & 4 & 5892 & 95 & & 4 & 5591 & 91 \\
\hline & 5 & 5716 & 93 & & 5 & 5343 & 87 \\
\hline & 6 & 5634 & 91 & & 6 & 5256 & 85 \\
\hline
\end{tabular}

